\title{
Analisis Validasi Pengembangan Moderen Pada Siswa Tunagrahita Di Slb Siswa Budhi, Surabaya
}

\author{
Pradana F.G.A ${ }^{a}$, Setyaningsih ${ }^{b}$, Rahmawati R.N $N^{c}$ Anisa A. $N^{d}$, Tinha R.A ${ }^{e}$ \\ a, b, c, d, eUniversitas Negeri Surabaya, Surabaya, East Java 60213, Indonesia
}

*Corresponding author: gilangpradana1182@yahoo.com

\begin{tabular}{l} 
A R T I C L E I N F O \\
\hline Article history: \\
Received 27 August 2018 \\
Received in revised form 08 \\
Nopember 2018 \\
Accepted 14 November 2018 \\
Keywords: \\
Motoric Development of \\
Special Children, learning \\
models, motor learning.
\end{tabular}

A R T I C LE INFO

Article history:

Nopember 2018

Accepted 14 November 2018

Keywords:

Motoric Development of

models, motor learning.

\begin{abstract}
A B S T R A C T
This research is an activity process to produce MODEREN (Motoric Development of Special Children) learning models which are developed to train motoric skills of mild mentally retarded children. The devices developed are modification tools and circuit learning methods. But in this writing focused on the process of validation testing through the construct test and the contents of the development tools made. The validators involved in this study were 5 people, namely Dr. Nanik Indahwati, M.Or. experts in the field of motor learning. Dr. Dwi Cahyo Kartiko. S.Pd., M.Kes. experts in the field of adaptive sports education. Andhega Wijaya S.Pd. Jas M.Or. experts in the field of learning media. Dra. Hj. Siti Mahmudah, M.Kes. experts in the field of social psychology and orthopedagogics of mentally retarded children. Drs. Edy Rianto, M.Pd. experts in penjas and adaptive sports. The final results of this study are MODEREN tools and models that are specifically for mild mentally retarded children to practice valid student motor skills.
\end{abstract}

\section{Pendahuluan}

Pendidikan merupakan hal yang sangat penting bagi suatu negara, karena salah satu syarat menjadi negara maju adalah dengan memperbaiki pendidikan. Pendidikan berarti menghasilkan, mencipta, sekalipun tidak banyak, sekalipun suatu penciptaan dibatasi oleh pembandingan dengan penciptaan yang lain (Piaget, 1896). Berdasarkan UU Nomor 20 Tahun 2003, pendidikan adalah usaha sadar dan terencana untuk mewujudkan suasana belajar dan proses pembelajaran agar peserta didik secara aktif mengembangkan potensi dirinya untuk memiliki kekuatan spiritual keagamaan, pengenalan diri, kepribadian, kecerdasan, akhlak mulia, serta keterampilan yang diperlukan dirinya, masyarakat, dan bangsa.
Semua orang berhak untuk mendapatkan pendidikan setingi mungkin, tidak terkecuali untuk anak yang memiliki kebutuhan khusus. Anak berkebutuhan khusus adalah anak dengan kharakteristik khusus yang berbeda dengan anak pada umumnya tanpa selalu menunjukkan pada ketidakmampuan mental, emosi, atau fisik. Menurut pasal 129 ayat 3 PP Nomor 17 Tahun 2010, peserta didik yang berkelainan terdiri atas peserta didik yang: tunanetra, tunarungu, tunawicara, tunagrahita, tunadaksa, tunalaras, berkesulitan belajar, lamban \ belajar, autis, memiliki gangguan motorik, menjadi korban penyalahgunaan NAPZA (Narkotika, Psikotropika, dan Zat Adiktif), dan memiliki kelainan yang lain.

$$
\text { Anak berkebutuhan khusus }
$$

membutuhkan bentuk pelayanan pendidikan khusus yang disesuaikan dengan potensi dan 
kemampuan masing-masing siswa. Menurut pasal 15 UU Nomor 20 Tahun 2003 tentang Sistem Pendidikan Nasional, bahwa jenis pendidikan bagi anak berkebutuhan khusus adalah pendidikan khusus. Menurut pasal 32 ayat 1 UU Nomor 20 tahun 2003, pendidikan khusus merupakan pendidikan bagi peserta didik yang memiliki tingkat kesulitan dalam mengikuti proses pembelajaran karena kelainan fisik, emosional, mental, sosial, dan memiliki potensi kecerdasan dan bakat istimewa. Tunagrahita merupakan salah satu dari kategori anak berkebutuhan khusus. Pendidikan untuk tunagrahita sendiri masih kurang diperhatikan oleh pemerintah karena cenderung fokus terhadap pendidikan umum, padahal setiap orang berhak untuk mendapatkan pendidikan yang sama meskipun dengan cara yang berbeda. Pendidikan tunagrahita lebih difokuskan pada perkembangan motorik, misalnya jenis gerak motorik, antara lain gerakan refleks, gerakan termodel, gerakan motorik halus, dan gerakan motorik kasar. Menurut Sherif (1965) manusia dalam berinteraksi dengan manusia lain selalu berhubungan dan dipengaruhi oleh lingkungan sekitarnya.

\section{Metode Penelitian}

Desain pengembangan dalam penelitian ini adalah Research and Development. Pengembangan yang digunakan yaitu dengan pengembangan alat modifikasi untuk siswa tunagrahita di SLB, yang secara prinsip sederhana, tetapi menjadi menarik bagi siswa, karena memiliki warna, dan bentuk yang bervariasi. Model pengembangan alat MODEREN menggunakan PLOMP, penjelasan Tiap tiap pengembangan dijelaskan sebagai berikut :

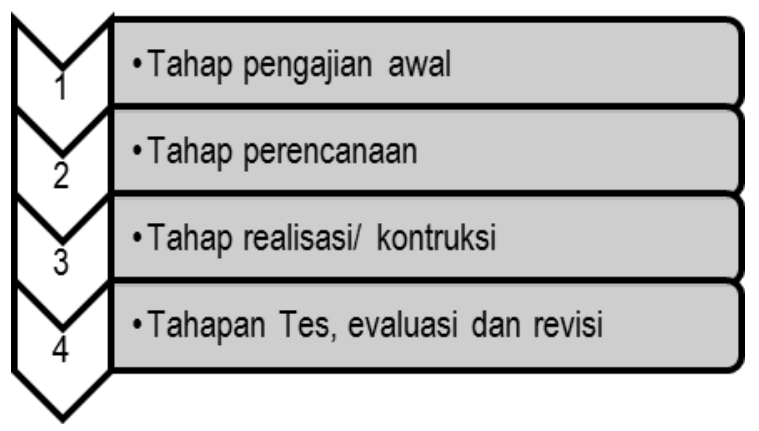

Gambar 1. Tahapan plomp (Tahmir, dalam Aminah, 2014)

Gambar diatas menjelaskan pengembangan perangkat terdiri dari, (1) Pengajian awal, (2) Tahap Perancangan, (3) Tahap realisasi/konstrusi, (4) Tahap tes, evaluasi dan revisi, dan tahap (5) Tahap implementasi, Dalam pelakasanaan penelitian ini menggunakan model Plomp yang dimodifikasi menjadi 4 tahapan (Aminah $\mathrm{N}$, 2014).

\section{Hasil dan Diskusi}

\section{Tahap investigasi awal}

Tahap investigasi yaitu peneliti melakukan analisis pembelajaran yang digunakan untuk menentukan masalah dasar yang diperlukan dalam proses pembelajaran. hasil observasi dan wawancara di SLB Siswa Budhi Surabaya, yang didapatkan sebagai berikut; (1) Pembelajaran PJOK hanya dilakukan pada hari jumat selama satu minggu; (2) Kegiatan pembelajaran PJOK hanya melakukan senam ceria $\mathrm{ABK}$, jalan sehat dan melakukan latihan motorik; (3) Anak tuna grahita yang mendapatkan nilai paling rendah untuk keterampilan motorik kasar karena merak dominan takut melakukan sesuatu hal yang baru; (4) Melakukan proses pemebalajarn motorik hanya menggunakan alat seadanya misalnya, kursi digunakan untuk kegiatan merangk dan tali digunakan sebagai titian; (5) Pembelajaran PJOK sebenarnya dapat dimaksimalkan karena 
mempunyai lapangan yang terletak di depan sekolah. Lemahnya pembelajaran PJOK terutama dalam keterampilan motorik siswa disebabkan terbatasnya sarana yang sangat sederhana dan kurang menarik, sehingga kurang memaksimalkan perkembangan motorik siswa tunagrahita.

\section{Tahap perencanaan}

Tahap perencanaan dilakukan dengan mendesain peralatan dan tujuan dari alat MODEREN, dalam hal ini peneliti merancang berbagai alat yang digunakan dalam pembelajaran MODEREN menggunakan sirkuit, dan terdiri dari 7 base dan disetiap base mempunyai 3 level kegiatan yang harus diselsaikan siswa tunagrahita. Merencanakan alat yang disesuaikan dengan karekteristik anak tungrahita ringan.

\section{Tahap realisasi/kontruksi}

Tahap ini peneliti membeli bahan yang dibutuhkan dan membuat membuat alat sesuai ukuran, warna, dan keguanaan dari setiap alat. Alat-alat MODEREN berupa alat modifikasi yang secara prinsip sederhana, tetapi akan menjadi menarik bagi siswa, karena memiliki warna dan bentuk yang bervariasi.MODEREN akan mengoptimalkan kemampuan guru dan juga alat modifikasi untuk meningkatkan motorik siswa tunagrahita. Pada sirkuit MODEREN akan terdapat beberapa base, di setiap base akan terdapat alat modifikasi yang berbeda dan juga jenis gerakan yang berbeda. Di setiap basenya akan terdapat gerakan yang memiliki tingkat kesulitan yang berbeda, mulai dari yang mudah, sedang, dan kemudian sulit. Tingkat kesulitan ini disesuaikan dengan kemampuan setiap siswa tunagrahita. Siswa tuangrahita harus melalui sirkuit secara urut, mulai dari base 1 hingga base 7 .

\section{Tahap pengujian, evaluasi dan revisi}

Pada tahap ini ada kegiatan yang dilakukan, yaitu melakukan validasi alat untuk mengetahui apakah alat dinyatakan layak atau tidak digunakan dalam proses pembelajaran, kegiatan kedua melakukan uji erbatar untuk mengetahui apakah alat praktis untuk digunakan, dan ketiga ujicoba lapangan setelah dinyatakan layak digunakan. Tahap ini bertujuan untuk mengetahui apakah MODEREN yang telah dibuat layal atau tidak berdasarkan pertimbangan dari pembimbing dan validator, alat yang layak digunakan dilapangan, dan apakah alat yang layak dapat meningkatkan keterampilan motorik siswa tunagrahita? Namun dalam pembahasan ini akan diuraikan untuk tujuan yang pertama yang dikembangkan dan divalidasi oleh validator untuk uji kelayak alat dalam proses pembelajaran.

\section{Validasi Alat MODEREN}

Hasil validasi MODEREN untuk melatih motorik siswa tunagrahita dinyatakan layak berdasarkan beberapa revi yang dilakukan, dapat dilihat tabel 1 berikut:

Tabel 1. Revisi MODEREN masukan dari Validator

\begin{tabular}{|l|l|l|}
\hline Base & $\begin{array}{l}\text { Sebelum } \\
\text { direvisi }\end{array}$ & Setelah direvisi \\
\hline $\begin{array}{l}\text { Woode } \\
\text { n Shoes }\end{array}$ & $\begin{array}{l}\text { Alat base } \\
1 \\
\text { menggun } \\
\text { akan kain } \\
\text { flannel }\end{array}$ & $\begin{array}{l}\text { Alat base 1 bahan yang dibuat dari } \\
\text { katu dan dilapisi kain oscar }\end{array}$ \\
\cline { 2 - 3 } & $\begin{array}{l}\text { Alat } \\
\text { hanya } \\
\text { dibuat 1 } \\
\text { ukuran }\end{array}$ & $\begin{array}{l}\text { Alat wooden shoes dibuat 2 size } \\
\text { yaitu besar dan kecil }\end{array}$ \\
\cline { 2 - 4 } & $\begin{array}{l}\text { Level } \\
\text { gerakan } \\
\text { hanya 2 }\end{array}$ & Level gerakan ada 3 \\
\hline $\begin{array}{l}\text { Boardi } \\
\text { ng } \\
\text { Walk }\end{array}$ & $\begin{array}{l}\text { Menggun } \\
\text { akan tali } \\
\text { untuk } \\
\text { meniti }\end{array}$ & Untuk neniti menggunakan kayu \\
\hline
\end{tabular}




\begin{tabular}{|c|c|c|}
\hline & $\begin{array}{l}\text { Level } \\
\text { hanya } 2\end{array}$ & Level dibuat 3 level \\
\hline & $\begin{array}{l}\text { Papan } \\
\text { balok } \\
\text { menempe } \\
1 \text { dengan } \\
\text { tanah }\end{array}$ & $\begin{array}{l}\text { Papan balok harus ada yang } \\
\text { menyenng kanan dan kiri sehingga } \\
\text { otomatis kesulitan level akan } \\
\text { meningkat }\end{array}$ \\
\hline & $\begin{array}{l}\text { Tidal ada } \\
\text { level } 3\end{array}$ & $\begin{array}{l}\text { Penembahan level } 3 \text { dengan papan } \\
\text { dibalik dan ditambahi dengan } \\
\text { balok kayu yang berwana warni } \\
\text { sehingg menarik }\end{array}$ \\
\hline \multirow[t]{3}{*}{ Tunnel } & $\begin{array}{l}\text { Alat } \\
\text { menggun } \\
\text { akan } \\
\text { hollahop }\end{array}$ & $\begin{array}{l}\text { Mengganti hollahop dengan kawat } \\
\text { yang diaatasnya terdapat jaring dan } \\
\text { siswa merangkak diatas papan dan } \\
\text { harus anam buat siswa }\end{array}$ \\
\hline & $\begin{array}{l}\text { Papan } \\
\text { tidak } \\
\text { berwarna }\end{array}$ & $\begin{array}{l}\text { Papan dilapisi kain oscar dan tidak } \\
\text { hanya menggunakan } 1 \text { warna tetapi } \\
2 \text { warna }\end{array}$ \\
\hline & $\begin{array}{l}\text { Level ke } 2 \\
\text { merangka } \\
\mathrm{k} \text { dengan } \\
\text { dua } \\
\text { hollahop } \\
\text { dan level } \\
3 \\
\text { merangka } \\
\mathrm{k} \text { dengan } \\
\text { diberi } \\
\text { batasan } \\
\text { waktu }\end{array}$ & $\begin{array}{l}\text { Level } 2 \text { merangkak dengan } \\
\text { instruksi maju dan mundur,dan } \\
\text { level } 3 \text { dengan indtruksi } \\
\text { mengambil gambar sesuai dengan } \\
\text { perintah guru }\end{array}$ \\
\hline $\begin{array}{l}\text { Ball } \\
\text { Pole }\end{array}$ & $\begin{array}{l}\text { Level } 2 \\
\text { meloncat } \\
\text { menyentu } \\
\text { h bola dan } \\
\text { level } 3 \\
\text { melompat } \\
\text { sesuai } \\
\text { dengan } \\
\text { instruksi } \\
\text { guru }\end{array}$ & $\begin{array}{l}\text { Level } 2 \text { melompat dengan } \\
\text { menyesuikan papan tumpuan dan } \\
\text { level } 3 \text { melompat sesuai dengan } \\
\text { instruksi dari guru tetapi pemilihan } \\
\text { warna secara acak dan area } \\
\text { lompatan harus sesaui dengan } \\
\text { warna }\end{array}$ \\
\hline \multirow[t]{2}{*}{$\begin{array}{l}\text { "O" } \\
\text { Walk }\end{array}$} & $\begin{array}{l}\text { Alat } \\
\text { mennggu } \\
\text { nakan } \\
\text { kun, anak } \\
\text { panah dan } \\
\text { lakban }\end{array}$ & $\begin{array}{l}\text { Alat menggunakan kayu yang } \\
\text { dibentuk bulat dan satu sama } \\
\text { lainnya dihubungkan dengan tali } \\
\text { dan setiap lingkaran dilapisi okain } \\
\text { oskar sehingg awarna dapat } \\
\text { bervariasi }\end{array}$ \\
\hline & $\begin{array}{l}\text { Level 1 } \\
\text { berjalan } \\
\text { kedepan } \\
\text { mengikuti } \\
\text { arah } \\
\text { lakban } \\
\text { Level } 2 \\
\text { berjalan } \\
\text { ke arah } \\
\text { belakang } \\
\text { mengikuti } \\
\text { lakban }\end{array}$ & $\begin{array}{l}\text { Level } 1 \text { berjalan lurus } \\
\text { Level } 2 \text { berjalan zigzag } \\
\text { Level } 3 \text { berjala mebentuk angka } 8\end{array}$ \\
\hline
\end{tabular}

\begin{tabular}{|c|c|c|}
\hline & $\begin{array}{l}\text { Level } 3 \\
\text { berjalan } \\
\text { sesuai } \\
\text { dengan } \\
\text { petunjuk } \\
\text { arah }\end{array}$ & \\
\hline \multirow[t]{3}{*}{$\begin{array}{l}\text { Side } \\
\text { Roll }\end{array}$} & $\begin{array}{l}\text { Kegiatan } \\
\text { melakuka } \\
\mathrm{n} \text { roll } \\
\text { depan }\end{array}$ & Kegiatan melakukan side roll \\
\hline & $\begin{array}{l}\text { Level } \\
\text { hanya ada } \\
2\end{array}$ & Level ada 3 \\
\hline & $\begin{array}{l}\text { Level } 1 \\
\text { roll depan } \\
\text { dengan } \\
\text { bantuan } \\
\text { guru } \\
\text { Level } 2 \\
\text { roll depan } \\
\text { sendiri }\end{array}$ & $\begin{array}{l}\text { Level } 1 \text { side roll dengan bantuan } \\
\text { guling dan guru } \\
\text { Level } 2 \text { side roll tanpa bantuan } \\
\text { guling tetapi dibantu guru } \\
\text { Level } 3 \text { side roll mandiri tanpa } \\
\text { bantuan guling dan guru }\end{array}$ \\
\hline $\begin{array}{l}\text { Forwar } \\
\mathrm{d} \text { and } \\
\text { back } \\
\text { roll }\end{array}$ & $\begin{array}{l}\text { Panjang } \\
\text { alat yang } \\
75 \mathrm{~cm}\end{array}$ & Panjang alat $1 \mathrm{M}$ \\
\hline
\end{tabular}

\section{Simpulan dan Rekomendasi}

Berdasarkan saran dari validator bahwa anak tunagrahita perlu adanya pendekatan khusus agar MODEREN dapat digunakan dalam prosen pemebelajaran PJOK khususnya anak tunagrahita ringan agar dapat meningkatkan keterampilan motorik siswa. Alat yang baik alah alat yang dapat menarik pernatian siswa dan keguaan alat sehinga dapat sesuai dengan tujuan pembeuatan alat MODEREN. Saran dari validator setiap alat yang di setiap base dapat dimaksimalkan oleh didwa untuk melakukan kegiatan secara mandiri dan meningkatkan keterampilan motoriknya. Daam hal ini revi dilakukan dengan menambahkan tujuan penggunaan alat disetiap base, perubahan bahan baku yang lebih aman untuk siswa, penambahan warana dan perubahan warana agar alat terlihat menarik bagi siswa. Perbaikan level base dari base 1 sampai base 7 harus dicamakan levelnya dikarenakan akan mempermulah untuk menentukan evaluasi atau penilaian terhadap hasil 
gerak siswa tunagrahita. Setelah alat selesai maka peneliti membuat modul dan video penggunaan MODEREN sehingga guru dapat ditaplikasikan secara mandiri.berikut adalah hasil perhitungan kelayakan alat MODEREN:

\section{Grafik 1. Hasil validai Alat MODEREN}

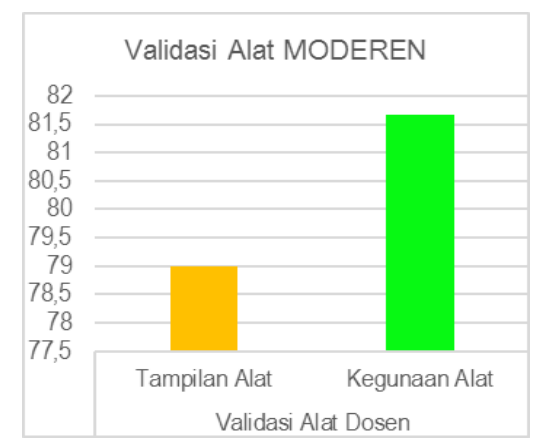

Berdasarkan gambar diatas kelayakan alat MODEREN diketahui bahwa tampilan alat dan kegunaan alat MODEREDN yang divalidas tergolong kategori "Baik" . Hasil ini akan menjadi acuan bagi penelitia dalam melakukan perbaikan agar memperoleh hasil yang maksimal.

\section{Daftar Pustaka}

Conny R, Semiawan. (2002). Belajar dan pembelajaran dalam taraf usia dini. Indonesia: PT Ikrar Mandiri Abadi.

Jose Jjoossee. (2012). Bermain sambil belajar. Diambil pada tanggal 18 Juni 2016 dari http://bermainsambilbelaja.blogspot.com/.

Moniqa Siagawati, dkk. 2007. Indigenous, Jurnal Ilmiah Berkala Psikologi volume 9, No.1, Mei 2007: 83-95.

Slamet Suyanto. (2005). Dasar-dasar pendidikan anak usia dini. Yogyakarta: Hikayat Publishing.

Sugiyono. 2007. Metode penelitian kuantitatif kualitatif dan $R \& D$. Bandung: Alfabeta.

Syaiful Hasan, dkk. Jurnal Pendidikan Olahraga, Volume 4, No. 2, Desember 2015

Haerani Nur. Jurnal Pendidikan Karakter tahun
III No. 1, Februari 2013: 87-9. Membangun Karakter Anak Melalui Permainan Anak Tradisional. Makassar.

Ukasyah Q.A.P dan Irfansyah. Jurnal Sosioteknologi Volume 14 No. 2, Agustus 2015: 124-140. Identifikasi Faktor-Faktor Permainan Tradisional Bebentengan sebagai Basis Perancangan Game Pemicu Peningkatan Sistem Motorik Anak. Bandung.

Tuti Andriani. Jurnal Sosial Budaya Volume 9 NO. 1, Januari-Juli 2012: 121-136. Permainan Tradisional dalam Membentuk Karakter Anak Usia Dini. Riau.

William Tedi. Sociologique Volume 3 NO. 4, Desember 2015: 1-17. Perubahan Jenis Permainan Tradisional menjadi permainan Modern Anak-Anak Di Desa Ijuk Kecamatan Belitang Hulu Kabupaten Sekadu. Pontianak

Hakimeh Akbar et al. Iranian Journal of Pediatrics Volume 19 No. 2, Juni 2009: 123-129. The Effect of Traditional Games in Fundamental Motor Skill Development in 7-9 Years Old Boys. Iran.

Tatjana Kovačević and Siniša Opić. Croatian Journal of Education Volume 16 No. , 2014: 95-112. Contribution of Traditional Games to The Quality of Student Relatian and Frequency of Student Socialization in Primary Education. Kroasia.

Jogen Boro et al. IOSR Journal of Humanities and Social Science (IOSR-JHSS) sVolume 20 Issue 3 Ver. V1, March 2015: 87-91. 